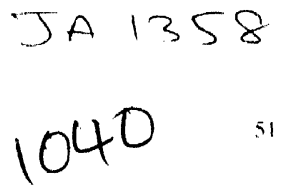

\title{
Pricing of the SDI service at ICRISAT
}

\author{
D. Jotwani and L.J. Haravu \\ ICRISA7. Patancheru. India
}

Received 9 July 1992

\begin{abstract}
The International Crops Research Institute for the Semi-Arid Tropies (ICRISAT) provides a monthly SI)I service to 364 users in over 50 countries. The service costs ahout US $\$ 25.00(1)$ per year and is funded partly hy a special project and partly hy core funds. (uts in core and project funds have forced the Institute to consider charging for the SDI service in order to offset as much as possible the cost of providing the service without hampering its accessibility to users who cannot pay. This paper identifies potentiat user segments who can be charged for the service using criteria such as capacity 10 pay. purpose of seeking information (profit-making is public good), and availability of information services in the institution or country of uscrs. 11 discusses different pricing objectives and pricing techniques, and describes the formula used to arrive at a price for users from the private sector.
\end{abstract}

\section{Introduction}

Limited budgets, rising salaries and other costs, growing user demands, pressures to ensure sustainability of information services funded by governments or by donors as in international agricultural research centres (IARCs) are facts of life. These have forced managers of publicly funded information services to charge for services even if only to establish the credibility and usefulness of their services. The Library and Documentation Services Division (LDSD) of ICRISAT, an IARC, has been providing SDI, literature search, abstracting, document delivery and information analysis services to users in several countries of the semi-arid tropics (SAT) in Africa and Asia. These services have been provided free of charge under special project funding of the International Development Research Centre (IDRC), Canada. The special project called SATCRIS (Semi-Arid Tropical Crops Information Service) builds its

Correspondence to: L.J. Haravu, Library and Documentation Services, ICRISAT, Patancheru, AP 502324, India.

Journal of Information Science 19 (1993) 51-55

Elsevier own database to provide SDI and search services. Project funds were used to obtain machine-readable data from database producers, for document delivery and for the production and distribution of abstracting services. However, cuts in the core budget of the LDSD and in project funds have forced SATCRIS to consider charging for its service. It was decided to experiment with charging for the SATCRIS SDI service and this paper presents our experience.

\section{The SDI service}

The SATCRIS SDI service is an automated service which alerts users each month to current information in specific areas of their interest. The service goes to 364 individuals in 50 countries and provides for regular feedback from users, analysis of which enables it to be fine-tuned to meet ongoing needs and changing interests. The SDI service is built around the in-house SATCRIS database which receives inputs in machine-readable form from two global databases, viz., CAB International, AGRIS, plus additional local input [1].

According to a rough estimate, ICRISAT spends US $\$ 25,000$ per annum for providing this service as follows:

$\begin{array}{lr}\text { Fixed costs } & \\ \text { CABl tapes service fee } & \$ 3,000 \\ \text { Staff salaries } & \$ 8.500 \\ \text { Suh total } & \$ 11.500 \\ \text { Variable costs } & \\ \text { Photocopying of outputs of standard profiles } & \\ \quad(5,00() \text { pages per month (a) Re 1.00/page*) } & \$ 2,400 \\ \text { Photocopying for document delivery } & \\ \quad(3,50) \text { pages per month (a) Re } 1.00 / \text { page*) } & \$ 1,680 \\ \text { Computer costs } & \$ 3,500 \\ \text { Mailing costs } & \$ 2,000 \\ \text { Overheads } & \$ 3,500 \\ \text { Sub total } & \$ 13,080 \\ \text { Grand total } & \$ 24,580 \\ \end{array}$

* US $\$ 1=$ Indian Rupees 25

It is difficult to accurately estimate the extent to which the fixed costs given above are in fact 
being utilised for the SDI service. For instance, the CABI tapes help in building the in-house database which is also used for on-demand and online searches. Similarly, staff costs shown above are not exclusively dedicated to SDI. Staff are also involved in data editing, indexing, and searching. For the purposes of this paper, however, we have taken the fixed costs given above as if they are dedicated to the SDI service. Using these figures, the average cost of providing the service is $\$ 5.75$ per user per month. Of the total cost shown above, LDSD annually spends US $\$ 7,100$ (tape fees + photocopying charges + document delivery) from its core budget towards the SDI service. A decision to examine the extent to which this expenditure could be offset by charging for SDl was made.

\section{The market and market segmentation}

The potential users of the SDI service can broadly be grouped into the following categories, in order of priority:

(1) ICRISAT scientists at all locations;

(2) scientists, researchers and others in National Agricultural Research Systems (NARS) and academic institutions of SAT countries;

(3) scientists, researchers and others in NARS and academic institutions of developed countries; and

(4) scientists, researchers and others in the profit-making (private) sector.

Although the service is primarily targeted at users in categories 1 and 2 above, others working on ICRISAT's crops also benefit from the service. A further segmentation of the user market reveals that, out of 364 users being served by the SDI (December 1991): 290 are working in 22 least developed (poor) countries, 41 in 14 developing countries, 18 in the newly developed countries and only 15 in the developed countries of the world (Fig. 1). Institution-type categorisation of SDI users shows that 190 of them are in research stations of different NARS, 109 work in academic establishments, 52 in IARCs and 13 are either private individuals or are working for private organisations (Fig. 2). An analysis of Fig. 3 further reveals that a significant $74 \%$ (269) users represent NARS and academic establishments of poor and developing countries.

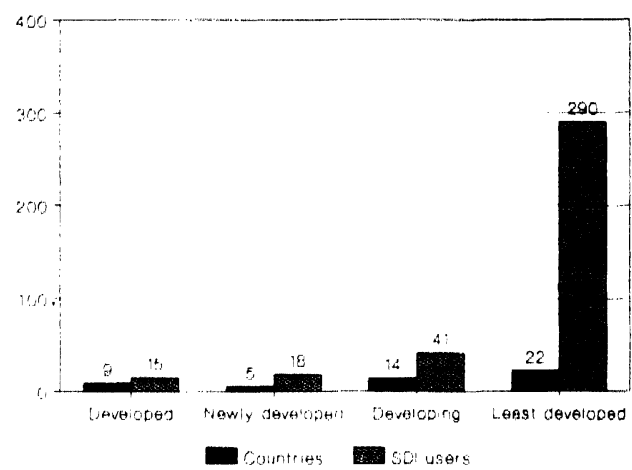

Fig. 1. Country-type distribution of the SDI service recipients.

Based on the above analysis, SDI users can now be regrouped into the following segments:

(1) users in ICRISAT and other IARCs;

(2) users in NARS of poor countries;

(3) users in academic establishments of poor countries;

(4) users in NARS of developing countries;

(5) users in academic establishments of developing countries;

(6) users from newly developed countries;

(7) users from developed countries;

(8) users from private sector.

In order to decide which of the above segments have the potential to be charged for the service, the following factors were thought to be important:

(a) users' capacity to pay;

(b) purpose of users in seeking information, i.e., public good e's profit-making;

(c) information infrastructure in the institution or country of users, i.e., the overall capacity of the institution/country to provide one or more components of a service, e.g. SDI.

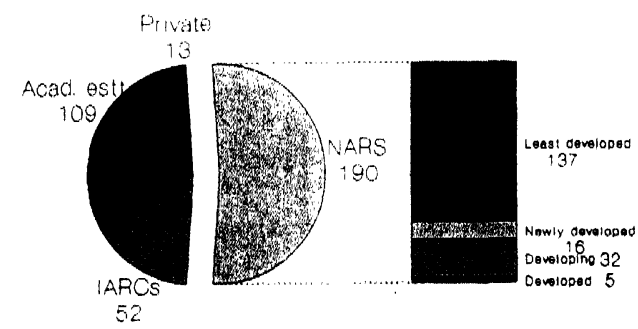

Fig. 2. Institution-type break-down of the SDI service recipients. 


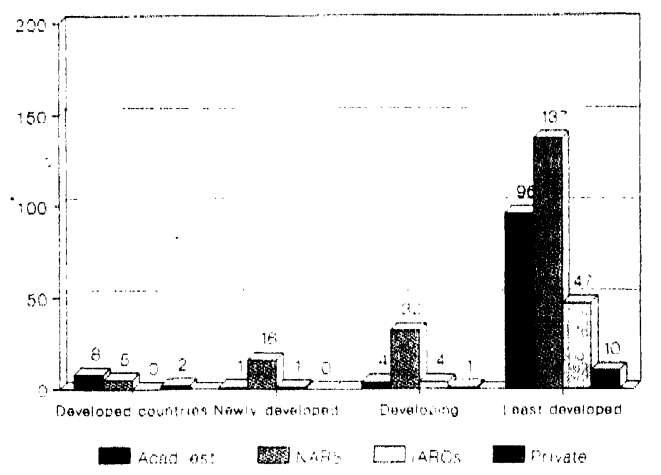

Fig. 3. Country/institution-type distribution of the SDI service recipients.

From the above segments, users from the private sector have the greatest ability to pay for the service. Users from developed countries are generally information conscious, their access to information is good and hence this segment can be considered next in order of priority for a fee-based service, particularly if the service has value-added components as in the case of the SATCRIS SDI service. Our experience shows that academic institutions in the newly developed and developing world have relatively better information infrastructures in comparison to research stations in NARS of such countrics, and can be considered as next in potential for being charged for information services.

\section{Pricing objective}

It is usual in developing a price for a service/ product to first determine the objective that is to be fulfilled. Keeping in view the overall mission of ICRISAT, it was decided that the pricing objective of the SDI service should be to offset, as much as possible, the costs of providing the service without hampering accessibility of the service to users who cannot (fully or partially) pay for the service, e.g., users in NARS of poor and developing countries.

The following pricing objectives discussed in traditional literature were examined [2]:
(a) profit maximisation;
(b) cost recovery;

(c) market incentive;

(d) market disincentive:

(e) social benefit.

None of the above pricing objectives, on its own. was consistent with the formulation of our pricing objective. It was recognised, however, that a combination of social benefit and cost recovery would probably be needed. This blending of objectives was felt would be helpful in a situation such as ours where the service is provided to users from academic, governmental, and private sectors and in 50 countries, classified as developed, newly developed, developing, and poor.

\section{Pricing methods}

A variety of pricing methods have been discussed in the literature to meet a given pricing objective [3]. These are:

\subsection{Cost-based pricing}

Refers to price set largely or even entirely on the basis of the costs. Typically, in cost-based pricing, all costs are included, usually with a somewhat arbitrary allocation of overheads made on the basis of expected operating levels.

\subsubsection{Alerage-cost pricing}

Covers all the fixed and variable costs associated with the product/service, and results in only one price common to all users.

\subsubsection{Marginal-cost pricing}

The cost resulting from the addition of the last unit output. It is the ratio of the increase in cost to the increase in output for small increment in output. It is generally lower than average cost.

\subsection{Demand-based pricing}

Looks at the intensity of demand rather than the level of cost to set a price. It is pricing based on what the consumer will bear or on what the perceived value of the product/service is. Lower prices are charged when or where demand is weak and higher prices are charged where demand is intense, even though unit costs may be the same in both cases. 


\subsubsection{Price discrimination}

In this method the product is sold at two or more prices with the price differentials not corresponding to differences in costs of production.

\subsection{Competition-based pricing}

When a product or service is priced by being based on what other organisations are charging for same product/service.

In view of the different market segments being served by SDI and also to achieve the objective of offsetting some of the costs of the service, it was thought that a blending of cost-based and demand-based (price-discrimination) pricing would yield the desired results.

\section{Pricing of SDI service}

It was decided to experiment first with the segment with the highest ability to pay for the service, i.e., the private sector. It was felt that this sector was also cost-conscious and its willingness to pay for the service could be taken as a definite indication of the usefulness of the service. Accordingly, 10 SDI users from seed companies, breweries, fertiliser and chemical industries and private consultants were asked to pay a calculated annual fee for the service. The annual fee was based on the average number of records that were output for a particular user in the last 12 months and the average number of photocopies that were supplied to him in this period. The following formula was used to arrive at the annual fee for a user:

$A F=\{[(R R) \times(R O)]+[P C]\} \times 12$

where $A F=$ Annual Fee

$\mathrm{RR}=$ Rate per record output

$\mathrm{RO}=$ Average number of records output per month

$\mathrm{PC}=$ Photocopying charges for 50 pages per month $@ \operatorname{Re} 1 /-$ per page

The SDI service has two types of user profiles. The first is a standard profile which provides output in broad topics, e.g., sorghum entomology, groundnut breeding. We found that a number of our users require this kind of current-awareness product which provides them with a browsing approach to current literature. Outputs based on standard profiles are photocopied for dispatch to users. The second kind of profile is a special profile or one created exclusively for a given user. Here the output is closely tailored to suit well defined interests [1]

A royalty fee of US $\$ 0.25$ is required to be paid to $\mathrm{CABI}$ for every record that is output in the SDI service. However, each time an original record is copied, as in standard profile outputs, the royalty fee is US $\$ 0.05$ for that record. We decided to retain these values as our rates per record output (RR) in the above formula since this is what we pay for outputting these records in the SDI service.

The above formula provides a distinct price for each user and is based on quantity of output and quantity of photocopies supplied (demand-based). Although the formula does not take into account salary costs, computer costs, mailing costs, and costs of photocopying of standard profiles, it does charge for the records (nearly $40 \%$ ) that are either received from AGRIS free of charge or input locally at the rate similar to $\mathrm{CABI}$ records.

All but one of the 10 private sector users willingly paid in advance for the service in 1991. In 1992, we recalculated the price for the service and found it to be less than the average cost in the case of 6 users. Only 3 users have been asked to pay more than the average cost of the service as the number of photocopies they requested during 1991 exceeded the stipulated 50 pages per month. In 1991 we recovered US $\$ 560$ from charging for the service and in 1992 we hope to recover US $\$ 566$ for the service.

We plan to charge another segment of market in the next stage i.e., users from developed countries, using the same pricing technique. Users from academic establishments of newly developed and developing countries are also planned to be charged after careful study. The fee to be charged for these users may be lower than what has been described earlier since they are more constrained for funds than their counterparts in developed countries or in the private sector. It is therefore proposed to charge these users only for copies of documents they request. The rationale for this is that most of these users, e.g., from agricultural universities, have access to local collections and need not depend upon international 
centres for document delivery. This will also help in better utilisation of local libraries in the provision of back-up and follow-up services.

Considering that the information infrastructure of the NARS in the developing and poor countries is still quite inadequate, there is no doubt that users from these countries will need to be provided with service free of charge until better access to information becomes possible through improved networking.

\section{Conclusion}

The willingness of users in the private sector to pay for the SDI service is evidence enough to show that the service has been found useful and the price suggested by us is acceptable to them. The pricing method adopted has been able to achieve our objective of offsctting some of the costs of production of the service without loss of clientele. The charges recovered are $8.75 \%$ of US $\$ 7,100$ which comes out of the budget of the LDSD, or $2.24 \%$ of total cost (US $\$ 25,(0)(1)$ ). As pointed out earlier, fixed costs are not necessarily apportionable only to the SDI service. On the face of it, the recoveries secm to be small and a negligible portion of total costs. However, these recoveries are only from one segment of the population (3\% of users, or 10 out of 364 users). The present experience encourages us to explore the potential for similar recoveries from other segments using a combination of demand-based and cost-based pricing.

Other information services/products which are client-specific, repackaged, and high-cost intensive are also candidates for pricing. These . include:
(a) literature search service;
(b) specialist abstracts service;
(c) information analysis products;
(d) document delivery service.

\section{References}

[1] L.J. Haravu, P.K. Sinha, S. Prasannalakshmi, D. Jotwani and R.G. Naidu, AGRIS level II and the information scrvices of specialized information analysis centers: the case of SATCRIS and its SDI service, IAALD Quarterly Bulletin $35(1)(199()) 11-18$.

[2] P. Kotler, Marketing for Nonprofil Organizations (Prentice Hall, Englewood (liffs, NJ. 1975).

[3] H.W. Zais, Economic modeling: an aid to the pricing of information scrvices, Journal of the American Society for Information Science 27 (1977) 89-45. 